\title{
Die biologische Wirksamkeit des fasergeführten Excimerlaserstrahls auf verschiedene organische Gewebe
}

\author{
R. Jahn, M. Dressel, H.U. Langendorff, W. Neu und K.H. Jungbluth \\ Abteilung Unfallchirurgie, Universitätskrankenhaus Eppendorf, Martinistraße 52, \\ W-2000 Hamburg 20, Bundesrepublik Deutschland
}

\begin{abstract}
Alle bisherigen Versuche, mit thermisch wirkenden Lasem Knochen zu schneiden, sind aufgrund der ausgedehnten Hitzeschäden des umliegenden Gewebes fehlgeschlagen. Bei den athermisch wirkenden Lasern mangelte es bislang an einer geeigneten Faser, um die notwendigen Energiemengen zu transmittieren.

Durch die Kombination von Excimerlasern mit größeren Pulsbreiten (60 ns und 250$300 \mathrm{~ns}$ ) und einer Taperfaser (Heraeus) gelingt eine effizientere Energieübertragung, die z.B. an Meniskusgewebe bereits Abtragtiefen von $6 \mathrm{~mm} / \mathrm{s}$ zuläßt. Auch am Knochen wurde anstelle von bisher $0,86 \mu \mathrm{m} /$ Puls eine Ablationsrate von $2 \mu \mathrm{m} /$ Puls erreicht. Eine der wichtigsten Voraussetzungen für eine carbonisationsfreie Ablation am Hartgewebe mit Excimerlasern ist das Applizieren der Laserenergie im wäBrigen Medium. Diese Bedingungen lassen die Eignung dieses Laser-Fasersystems bereits für arthroskopische Operationen erkennen.
\end{abstract}

